\title{
Back azimuth constrained double-difference seismic location and tomography for downhole microseismic monitoring
}

\author{
Yukuan Chen ${ }^{1,2}$, Haijiang Zhang ${ }^{1,2^{*}}$, Yuanyuan Miao ${ }^{3}$, Yinsheng Zhang ${ }^{3}$, Qiang Liu $^{3}$ \\ ${ }^{1}$ Wantai Microseismic Lab of School of Earth and Space Sciences \\ University of Science and Technology of China, Hefei, 230026, China \\ Corresponding author: E-mail: zhang11@ustc.edu.cn \\ ${ }^{2}$ Laboratory of Seismology and Physics of Earth's Interiors \\ University of Science and Technology of China \\ Hefei, 230026, China \\ ${ }^{3}$ Anhui Wantai Geophysical Technology, Hefei, 230026, China
}

Submitted to Special Issue: Microseismicity

Physics of the Earth and Planetary Interiors

February 21, 2016

Revised on October 7, 2016

(C) 2016. This manuscript version is made available under the Elsevier user license http://www.elsevier.com/open-access/userlicense/1.0/ 


\section{ABSTRACT}

We have developed a new seismic tomography method, back azimuth constrained double-difference (DD) seismic tomography, which is suitable for downhole microseismic monitoring of hydraulic fracturing. The new method simultaneously locates microseismic events and determines three-dimensional (3D) Vp and Vs models for the fracturing zone using differential arrival times from pairs of events and event back azimuths in addition to absolute arrival times. Compared to the existing DD location and tomography method, our method incorporates back azimuth information to better constrain microseismic event locations in the case of poor spatial station coverage such as the linear downhole seismic array generally used for microseismic monitoring. By incorporating the relative arrival time and back azimuth information of events, the extended DD method can provide better relative event locations, and thus can better characterize the fracture distribution. In addition to microseismic locations, seismic velocity anomalies determined around the fracturing zone may also provide valuable information for fracture development. Due to the existence of fractures and fluids, the seismic velocity is expected to be lower in the fractured zone compared to the surrounding regions. Therefore the area of low seismic velocity anomaly may be used as a proxy for the stimulated reservoir volume. We have applied the new method to a downhole microseismic dataset from shale gas hydraulic fracturing. The microseismic events are more accurately relocated than the conventional grid search location method, and they are generally associated with low velocity anomalies. 
Key words: Downhole microseismic monitoring; double-difference tomography; shale gas fracturing; stimulated reservoir volume

\section{INTRODUCTION}

Microseismic monitoring has gradually become a common technique to characterize the development of hydraulic fracturing in tight sand and shale gas reservoirs (Rutledge \& Phillips 2003; Maxwell et al. 2010; Zimmer 2011b; Li et al. 2011; Yang et al., 2013). By analyzing the associated microseismicity during a hydraulic fracturing operation, it can provide important insight into the fracture development pattern and fluid migration (Zhang et al. 2009). For example, by knowing precise locations of microseismic events induced by hydraulic fracturing, it can bring important constraints on fracture distribution and development in the hydraulically stimulated reservoir (e.g. Rutledge \& Phillips, 2003). Downhole microseismic observation system is generally used for continuously monitoring the hydraulic fracturing process, in which a string of receivers are installed in a borehole, or at some cases in two or three boreholes close to the fracturing spot. For downhole microseismic monitoring, the back azimuth information of the seismic wave arriving at the receivers is critical for locating an event because of the limited receiver aperture (Pearson, 1981; Phillips et al. 1989; Fischer et al. 2008). The event back azimuth may be determined directly from the P-wave because its particle polarization is parallel to the raypath direction in an isotropic medium. For accurately locating microseismic events using arrival times, it requires to have accurate first arrival picks and an accurate velocity model. 
However, there are generally picking errors in first arrival times. For the velocity model used for event location, it is generally a one-dimensional model derived from sonic logging, and is often calibrated by perforation shots.

To mitigate the issue of arrival time picking errors, waveform cross-correlation (WCC) and event-clustering techniques can be used to improve arrival time estimates or determine high-precision relative arrival times (VanDecar \& Crosson, 1990). Based on these techniques, Waldhauser and Ellsworth (2000) developed a double-difference (DD) location method, which can determine high-resolution hypocenter locations by incorporating more accurate $\mathrm{P}$ - and/or S-wave differential arrival-time measurements. Furthermore, it is capable of partly eliminating the unmodeled common velocity errors existing along the ray paths between a closely spaced cluster of events and a receiver. Recently, DD location method has been used to relocate microseismic events, showing that the diffuse locations can be collapsed into a sharper image of seismicity (Castellanos \& Baan, 2013). Li et al. (2013) extended the DD location method to the downhole microseismic monitoring system to locate microseismic events induced by hydraulic fracturing and to determine anisotropic parameters for the 1D anisotropic model by using differential arrival times and differential back azimuths.

Microseismic locations have been used to determine the stimulated reservoir volume (SRV) due to hydraulic fracturing by finding a volume encompassing the microseismic events (Mayerhofer et al. 2010; Zimmer 2011a). This is based on the assumption that hydraulic fracturing is associated with high-frequency microseismic events and these events can be detected and accurately located. However, due to weak signal levels, some microseismic events 
cannot be detected. For some fracking stages, high-frequency microseismic events may not be induced; instead long-period long-duration (LPLD) seismic events are associated with the fracking process (Das \& Zoback, 2011, 2013a, 2013b). For this reason, the SRV estimated solely based on microseismic locations may not be accurate. In addition to microseismic locations, seismic velocity structure around the fracturing zone may also provide valuable information for fracture development. During the hydraulic fracturing, high-pressure fluids are injected into target zones to create fractures to enhance the reservoir permeability. Thus, due to the existence of fractures and fluids, the stimulated reservoir is expected to have lower seismic velocity. Therefore, the areas of the low seismic velocity anomaly may be used as a proxy for SRV.

In this study, we extend the DD tomography method to include the event back azimuth information to better constrain event locations for the case of downhole microseismic monitoring. We use the extended DD seismic tomography method to simultaneously solve for the three-dimensional $\mathrm{Vp}$ and $\mathrm{Vs}$ models and microseismic locations using both absolute and differential arrival times from event pairs (Zhang \& Thurber, 2003). Compared to the conventional location and tomography method, it has the advantage to better determine the source region velocity anomalies and relative event locations. In the rest of the paper, we will first introduce the extended DD tomography method and then apply it to a downhole microseismic dataset to show its effectiveness.

\section{METHODOLOGY}


DD seismic tomography method (Zhang \& Thurber, 2003) is developed from the DD location method (Waldhauser \& Ellsworth, 2000), which makes use of both absolute arrival times and more accurate differential arrival times to simultaneously solve for the 3-D velocity models (Vp and Vs) and seismic event locations. A brief summary of this method is described as follows.

Based on the ray theory, the body-wave arrival time $T$ from an earthquake $i$ to a seismic station $k$ is expressed as a path integral,

$$
T_{k}^{i}={ }^{i}+{ }_{i}^{k} u d s
$$

where $\quad{ }^{i}$ is the origin time of event $i, u$ is the slowness field, and $d s$ is an element of path length. Generally, a truncated Taylor series expansion is used to linearize Equation (1),

$$
r_{k}^{i}=\sum_{l=1}^{3} \frac{\partial T_{k}^{i}}{\partial x_{l}^{i}} x_{l}^{i}+{ }^{i}+\int_{i}^{k} u d s
$$

where $r_{k}^{i}$ is the misfit between the observed and modeled arrival times, $\Delta x_{l} \quad(l=1,2,3)$ and $\Delta u$ are the perturbations of the hypocenter in three directions and slowness along the ray path, respectively.

If we take the difference between the arrival time residuals from event pairs $i$ and $j$ to a common station $k$, we have

$$
r_{k}^{i} \quad r_{k}^{j}=\sum_{l=1}^{3} \frac{\partial T_{k}^{i}}{\partial x_{l}^{i}} x_{l}^{i}+\quad{ }^{i}+\int_{i}^{k} u d s \sum_{l=1}^{3} \frac{\partial T_{k}^{j}}{\partial x_{l}^{j}} x_{l}^{j} \quad{ }^{j} \quad \int_{j}^{k} u d s .
$$

This is the so-called DD tomography method (Zhang \& Thurber, 2003). The difference between observed and modeled differential arrival times for the two events can also be defined as 


$$
d r_{k}^{i j}=r_{k}^{i} \quad r_{k}^{j}=\left(\begin{array}{ll}
T_{k}^{i} & T_{k}^{j}
\end{array}\right)^{o} \quad\left(\begin{array}{ll}
T_{k}^{i} & T_{k}^{j}
\end{array}\right)^{m}
$$

The observed differential arrival times $\left(T_{k}^{i} T_{k}^{j}\right)^{o}$ can be calculated by the WCC technique, which can significantly improve the accuracy of first arrival pickings.

For downhole microseismic monitoring, a string of receivers are generally installed in a vertical well, providing a poor azimuthal coverage for microseismic events. For this reason, the back azimuth information of microseismic events is needed to provide an additional constraint to determine their absolute locations. Here we add the back azimuth constraint to each event in inversion to make sure the event is located along a predefined azimuth (Fig. 1). The back azimuth constraint for event $i$ can be expressed as follows,

$$
x_{1}^{i} \tan \left({ }^{i}\right) x_{2}^{i}=0
$$

where $\varphi^{i}$ is the back azimuth of event $i$, which can be obtained from the eigenvectors of the covariance matrix of the horizontal-component seismograms (Magotra et al. 1989). Then the back azimuth constrained DD tomography method for downhole microseismic monitoring can be expressed as $\left\{\begin{array}{l}r_{k}^{i}=\sum_{l=1}^{3} \frac{\partial T_{k}^{i}}{\partial x_{l}^{i}} x_{l}^{i}+{ }^{i}+\int_{i}^{k} u d s \quad \text { For absolute } \mathrm{P} \text { or S data } \\ r_{k}^{i} \quad r_{k}^{j}=\sum_{l=1}^{3} \frac{\partial T_{k}^{i}}{\partial x_{l}^{i}} x_{l}^{i}+{ }^{i}+\int_{i}^{k} u d s \sum_{l=1}^{3} \frac{\partial T_{k}^{j}}{\partial x_{l}^{j}} x_{l}^{j} \quad \int_{j}^{k} u d s \quad \text { For differential P or S data } \\ x_{1}^{i} \quad \tan \left(\begin{array}{c}i \\ 1\end{array} x_{2}^{i}=0 \text { For event } \mathrm{i}\right.\end{array}\right.$ 
As illustrated in Fig. 1, ray paths from two nearby events to a common receiver will substantially overlap outside the source region, meaning that the path anomalies outside the source region for two events will essentially cancel out by using differential arrival times based on Equation (6). This is one of the reasons that the DD tomography method is able to produce more accurate event locations and velocity anomalies near the source region than standard tomography using absolute arrival times.

It has been noted that ignoring the coupling effect between the event hypocenters and the velocity structure can lead to significant biases in the resulting velocity models (Thurber, 1992). Therefore for our extended DD tomographic system we simultaneously resolve the event locations and velocity models. However, it may be problematic to combine the source parameters (location and origin time) and the slowness model parameters into one inversion system. This is because the sensitivities of seismic arrival times to source and slowness model parameters may be quite different. For example, for the downhole microseismic monitoring system shown in Figure 2, the sensitivities of travel times with respect to location parameters vary from 0.1 to 0.3 $\mathrm{s} / \mathrm{km}$, while the sensitivities of travel times with respect to slowness model parameters are about $0.015 \mathrm{~km}$ on average. To overcome this problem, following Zhang and Thurber (2003) we applied the column scaling to the inversion matrix system based on Equation (6) to balance different contributions of source and slowness model parameters to fit for arrival times.

To realize the extended DD tomography method, we adopt an approximate pseudo-bending ray-tracing algorithm (Um \& Thurber, 1987) to find the rays and calculate the travel times between events and stations. The model is represented by velocity values specified on a regular 
set of 3-D nodes and the velocity values are interpolated by using the trilinear interpolation method for the points not located at grid nodes. The hypocentral partial derivatives are calculated from the direction of the ray and the local velocity value at the source (Lee \& Stewart, 1981). To calculate the slowness model partial derivatives, which are simply ray path lengths, the ray path is divided into a set of small segments and the segment length is allocated to the neighboring 8 grid nodes around the segment midpoint proportional to their interpolation weights on the segment midpoint (Thurber, 1983).

In the extended DD tomographic system, there are different types of data including the absolute arrival times, the catalog differential arrival times, and the more accurate WCC data. To incorporate different types of data into one inversion system, we adopt a hierarchical weighting scheme at different stages of inversion (Zhang \& Thurber, 2003). In the first several iterations, we apply greater weight to the catalog arrival time data to obtain the large-scale locations and velocity structure. Then the catalog differential data and WCC data are successively weighted more to further refine the event locations and the velocity structure near the source regions. Considering that arrival time residuals are more linear to slowness model parameters than event location parameters, we alternate one iteration of simultaneous inversion with two iterations of only relocating events to assure the convergence of event locations. To regularize the inverse problem, both smoothing and damping regularization methods are adopted to make the inversion more stable. For the augmented tomographic system with smoothing and damping regularizations, the LSQR algorithm (Paige \& Saunders, 1982) is applied, which has the advantage of efficiently solving for large and sparse inverse system. 


\section{APPLICATION TO A DOWNHOLE MICROSEISMIC DATASET}

To test our new method, we apply it to a microseismic dataset recorded on a downhole linear seismic array deployed for monitoring shale gas fracturing in an oil field in China. In the monitoring well, there are 12 three-component receivers with the receiver spacing of $30 \mathrm{~m}$. The array begins at $2135 \mathrm{~m}$ in depth and spans $330 \mathrm{~m}$ vertically (Fig. 2a). The target fracturing shale layer is at $2440 \mathrm{~m}$ in depth. There are 15 fracturing stages and we only use 2297 events detected for stages 10 to13. The sampling rate of the recorded continuous data is $0.5 \mathrm{~ms}$. For locating microseismic events, the 1D P-wave and S-wave velocity profiles between 2000 and $2700 \mathrm{~m}$ are extracted from acoustic sonic logging data (Fig. 2b).

First we use the perforation shots to determine the orientation of the horizontal components of the $3 \mathrm{C}$ receivers in the vertical monitoring well. As the locations of perforation shots are known, their back azimuths are also known with respect to borehole receivers and can thus be used to mathematically rotate horizontal components to north and east directions. The observed back azimuth for the perforation shot recorded on each receiver is obtained from the eigenvector analysis of the covariance matrix constructed from the horizontal component seismograms (Magotra et al., 1989). The angle difference between observed and theoretical back azimuths is then used to rotate receivers. For this dataset, 12 perforation shots are used for calculating the rotation angles for each receiver and the average rotation angle is eventually used for rotating the corresponding receiver. Fig. 3 shows the comparison of the waveforms from a perforation shot 
before and after orientation. After the orientation, polarities of the horizontal components at all receivers are consistent for the perforation shot.

In the case of microseismic monitoring using only one vertical well, it is not possible to determine the absolute event location by using only arrival times because of the symmetry between the linear receiver array and the $1 \mathrm{D}$ velocity model. Therefore it requires additional polarization information of the incoming waveform (e.g., Pearson 1981; Eisner et al. 2009; Jones et al. 2010), usually the back azimuths, to constrain the event location along with event arrival times at each receiver. Conventionally, back azimuth constrained grid search location method is used to find the optimal event location and origin time that can fit arrival times of P- and/or $\mathrm{S}$-wave at each receiver. However, it is known that the use of arrival times from a single phase leads to a trade-off between the origin time and distance from a vertical array (Eisner et al. 2010). Therefore here we choose to fit for the differential S-P arrival times to mitigate the coupling between the origin time and event location in our back azimuth constrained grid search location procedure.

For the grid search location method, we select a grid interval of $4 \mathrm{~m}$ in three dimensions. The location results for some selected stages are shown in Fig. 4. After relocation, the root-mean-square (RMS) S-P travel time residual is $6.3 \mathrm{~ms}$, indicating that the event locations fit fairly for the observed arrival times. Overall, we can see in the horizontal plane, the event locations can be categorized into two groups. One group consists of events that are located in zones normal to the well trajectory. This is no surprise because the well is drilled along the minimum horizontal compressive stress direction and the created fractures tend to be parallel to 
the maximum horizontal compressive stress direction that is normal to the well trajectory. The other group of events forms a linear trend that is about $45^{\circ}$ clockwise oblique to the well trajectory. Although the events are clustered into several linear streaks, they still appear scattered to some extent.

On one hand, the scattered event locations are caused by the limited grid interval used for grid search procedure. On the other hand they are also due to errors in phase picks and in the 1D velocity model used for location. To further refine event locations, we apply the extended DD tomography method to simultaneously determine event locations and the 3D velocity models using more accurate waveform cross-correlation data. The bispectrum-verified waveform cross-correlation method is used to obtain more accurate relative arrival time delays for pairs of microseismic events at the same receiver (Du et al. 2004). Generally, time delays with associated CC coefficients larger than a chosen threshold are selected for DD location and tomography. However, when two similar time series are contaminated by correlated noise sources, the relative time delay between them calculated with the $2^{\text {nd }}$ order CC technique is sometimes not reliable. In comparison, the bispectrum method, which works in the third-order spectral domain, can eliminate correlated Gaussian noise sources in two similar time series and thus can be used to check the reliability of the $\mathrm{CC}$ determined time delay. Fig. 5 shows that for several similar waveforms when they are aligned according to catalog picks there exists some waveform misalignment. As a result, the stacked waveform has relatively lower amplitude. When they are aligned according to WCC delay times, the waveform alignment is greatly improved based on 
the fact that the stacked waveform has higher amplitude than that corresponding to the waveform alignment by catalog first arrival picks (Fig. 5).

Through the bispectrum-verified waveform cross-correlation, we obtained 2,391,939 P cross correlation times and 787,796 cross correlation S times. For the extended DD tomography, we used 26,354 absolute catalog P and 23,891 absolute catalog S arrival times. We also constructed 477,462 catalog differential $\mathrm{P}$ arrival times and 403,655 differential $\mathrm{S}$ arrival times directly from absolute picks. On average, each event is linked to 20 neighboring events and the average inter-event distance is $27 \mathrm{~m}$. The inversion grid points are at $\mathrm{X}=-0.4,-0.3,-0.2,-0.1,0$, $0.05,0.1,0.15,0.2,0.25,0.3,0.4 \mathrm{~km}$, and at $\mathrm{Y}=-1,-0.8,-0.7,-0.65,-0.6,-0.55,-0.5,-0.45,-0.4$, $-0.3,-0.2,0 \mathrm{~km}$, respectively. The nodes in depth are positioned at $2.123,2.175,2.227,2.252$, $2.277,2.300,2.322,2.353,2.384,2.407,2.432,2.465,2.498,2.531,2.564,2.600,2.650$, and $2.700 \mathrm{~km}$, respectively (Fig. 2). After the inversion, the absolute RMS residual for catalog times decreases from $6.2 \mathrm{~ms}$ to $4.0 \mathrm{~ms}$, and from $6.6 \mathrm{~ms}$ to $0.4 \mathrm{~ms}$ for cross correlation times.

Fig. 6 shows the event locations for selected stages of 10-13. Compared to event locations by back azimuth constrained grid search location method (Fig. 4), the event locations look more concentrated into linear streaks in the map view, and are closer to the fracturing well at the depth. Fig. 7 shows the comparison of all event locations between the grid search location method and the DD tomography method for stages $10-13$. For both methods, most microseismic events are located to the east of the well trajectory because of their proximity to the monitoring well. As seen for the individual stages of 10-13, relocated events are formed into two groups: one approximately perpendicular to the horizontal well trajectory in the map view, and the other 
intersecting with the well trajectory obliquely in the azimuth of about $45^{\circ}$. However, there are some notable differences in spatial distribution of microseismic events for two methods. In the map view, the DD tomography method results in more clustered microseismic events (marked by black circles in Fig. 7a and b), indicating a sharper image of seismicity and fractures. In the Y-Z cross sections, the events are distributed in bands at different depths for both methods. In comparison, the microseismic events in different bands from the DD tomography method are closer to the fracturing well. Most events are distributed above the fracturing depth, similar to most other fracturing jobs in North America (e.g. Yang et al., 2013; Erwemi et al., 2010).

Fig. 8 shows the inverted Vp and Vs models at depths of 2.353, 2.432 and $2.498 \mathrm{~km}$, respectively. It is clear that $\mathrm{Vp}$ and Vs models show consistent velocity structures although there are some differences between two models. For the depth slice of $2.353 \mathrm{~km}$, there exists an evident low velocity anomaly zone $(\mathrm{Vp}=3.8 \mathrm{~km} / \mathrm{s}$ and $\mathrm{Vs}=1.9 \mathrm{~km} / \mathrm{s})$ compared to the surrounding region $(\mathrm{Vp}=4.4 \mathrm{~km} / \mathrm{s}$ and $\mathrm{Vs}=2.4 \mathrm{~km} / \mathrm{s})$ between relocated microseismic events and the monitoring well. Microseismic events are located on the western edge of the low velocity anomaly zone. For the depth slice of $2.432 \mathrm{~km}$, the group of events that intersect with the well trajectory obliquely is clearly associated with low Vp and Vs anomalies. For the deeper horizontal slice at $2.498 \mathrm{~km}$, the linear streak of microseismic events is still slightly associated with low velocity anomalies but a more apparent low velocity anomaly zone is located to the southeast of the linear streak of events.

To test the resolution of the inverted Vp and Vs models, we performed a checkerboard resolution test. We added $\pm 10 \%$ anomalies alternatively to each grid node in three dimensions to 
the starting Vp and Vs models. The synthetic times are calculated based on the checkerboard models according to the real event and station distribution. We then added Gaussian random noise with zero mean and a standard deviation of $1 \mathrm{~ms}$ to all the catalog $\mathrm{P}$ and $\mathrm{S}$ times considering the sampling rate of the waveform is $0.5 \mathrm{~ms}$. In addition, we also added a constant noise term to the arrivals at each station from a uniformly distributed random noise between -2.5 $\mathrm{ms}$ and $2.5 \mathrm{~ms}$, which simulates the case that there exist systematic errors associated with modeling and picking biases (Zhang \& Thurber, 2003). The synthetic travel times are used for inversion with the same inversion strategies as the real data. The recovered checkerboard models at depths of 2.353, 2.432 and $2.498 \mathrm{~km}$ (Fig. 9) show that our proposed extended DD tomography method is able to resolve the velocity structure around the fracturing depth zone under the current event and station distribution.

Fig. 10 further shows the inverted Vp and Vs perturbations with respect to the average values in the $\mathrm{Y}-\mathrm{Z}$ plane through $\mathrm{X}=0.05 \mathrm{~km}$, and their recovered checkerboard models, respectively. It is clear that around the depth of $2.35 \mathrm{~km}$ above the fracturing zone there exists a band of low velocity anomaly, which is also associated with active microseismicity. Around the fracturing zone both below and above the fracturing well, the microseismic events are associated with clear low Vs anomalies. In comparison, not all of microseismic events are associated with low $\mathrm{Vp}$ anomalies around the fracturing zone. It can also be seen that the band of low velocity anomaly at the depth of $2.35 \mathrm{~km}$ and the low velocity anomaly zone around the fracturing well are more likely to be separated, rather than connected. 


\section{DISCUSSIONS}

For downhole microseismic monitoring by a vertical single well, it is important to have accurate estimation of back azimuth for each event in order to accurately determine its absolute location. Generally, back azimuths obtained from particle polarization analysis have considerable uncertainties. Eisner et al. (2009) showed that back azimuths derived from P or S waves have a standard deviation of $29^{\circ}$ and $10^{\circ}$, respectively. In this study, the back azimuth for each event is estimated from averaging calculated back azimuths at all receivers recording the event. Each event we analyzed is recorded by at least 5 receivers and in fact many events are recorded by more than 9 receivers. The standard deviation of the estimated back azimuth for each event is smaller than $8^{\circ}$, likely due to high signal to noise ratio (SNR) of microseismic events used in this study.

From the comparison of event relocations by the grid search and DD tomography methods (Fig. 7), it can be seen that the DD tomography method results in more clustered events, thus the fractures could be better characterized from event relocations. This is mainly because more accurate WCC times are used and the velocity models are also simultaneously determined in the extended DD tomography. This fact is corroborated by substantially lower RMS residual for the WCC times than the catalog times. It is also further verified by the distribution pattern of the WCC coefficients for close events. It is generally true that when two events are closer their waveforms will be more similar. For the events located by the grid search location method, many event pairs have similar waveforms even when they are separated by more than $0.5 \mathrm{~km}$ (Fig. 11). 
This large event separation is likely due to greater uncertainties in absolute event locations (Castellanos\& Baan, 2013). In comparison, after relocating by the DD tomography method there is a trend that event separation is smaller for event pairs with similar waveforms (Fig. 11). This change is due to more accurate relative event locations produced by the DD tomography method.

For stages 10 to 13 , microseismic events fall into two groups: one approximately normal to the horizontal well trajectory and the other oblique to the well trajectory (Figures 6 and 7). For the group of events that are distributed normal to the well trajectory, they are more likely to be directly related to the fracturing process because the induced fractures tend to be aligned parallel to the maximum horizontal compressive stress direction. In comparison, for the group of events that are linearly distributed obliquely to the well trajectory, they are more likely induced by the activation of the existing faults by fluid injection. This phenomenon of activated slip along a pre-existing fault has been reported in previous studies (e.g. Yang et al., 2013). Fig. 7 shows that two faults were likely activated during stages $10-13$. For stages 10 and 11 , the eastern fault is first activated while the western fault is later activated during stages 12 and 13 (Fig. 7). These events induced by fault activation clearly form linear streaks that follow fault strikes. Because of existing faults around the fracturing zone, this could cause the loss of fracturing fluids and induce relatively larger-size microseismic events (Ellsworth, 2013).

In addition to more accurate event locations, our extended DD tomography method also provides 3D velocity variations around the fracturing zone. For those microseismic events caused by activation of the existing faults, they are associated with low velocity anomalies (Fig. 8). This is because these faults intersect with the fracturing well and the fluid injection into the 
well can cause the infiltration of fluids into the existing faults. Essentially these existing faults act as flow paths for transporting fluids away from the injection spots (Ellsworth, 2013). Because of the increased fluid pore pressure in the fault zones, both Vp and Vs values will be decreased (Christensen, 1989), forming low velocity anomaly zones seen on the velocity models from the DD tomography method (Fig. 8). It was previously reported that in another shale gas fracking job microseismic events are located as far as $1 \mathrm{~km}$ away from the fracturing well due to the existing fault acting as a flow path for the fluids infiltrating quickly away from the injection well to induce many microseismic events in a fracture-rich zone (Zeng et al., 2014). In this study these existing faults identified from event relocations also likely help to transport fluids into the weak or fractured zone above the fracturing depth, causing the band of microseismicity and low velocity anomaly around the depth of $2.35 \mathrm{~km}$ (Fig. 10). This is similar to the findings of isolated microseismic events within individual sand intervals by activating the reservoir's prevalent natural fractures by Rutledge et al. (2003).

It is also found that right above and below the fracturing well the induced microseismic events are clearly associated with low Vs anomalies (Fig. 10). By comparing the recovered checkerboard patterns for Vp and Vs, it can be seen that the Vs model is better resolved around the fracturing well (Fig. 10). The low Vs anomalies can be interpreted due to changes of the rock properties of the target shale layer by the fracturing process with high-pressure fluid injection. It is expected that fracturing process creates small fractures and increases the porosity in the fracturing zone. As a result of the existence of fractures and fluids, the pore pressure of the fracturing zone is also expected to be high. The lab experiments showed that with the increase of 
pore pressure and porosity (Christensen, 1989), the Vp and Vs would be reduced. Based on these laboratory observations, the low $\mathrm{Vp}$ and low Vs anomalies associated with fracturing zone are most likely caused by high pore fluid pressures and high porosity due to existence of fractures and fluids in the zone. Therefore, the anomaly zone with low Vp and low Vs can be used as a proxy for the SRV estimation.

It has been a challenge to solely rely on microseismic events to delineate the fracture distribution and estimate the SRV because of incompleteness of event detection and location due to low SNR. However, for the extended DD tomography it only relies on a certain amount of larger events to determine the velocity anomalies of the target fracturing zone to be used for estimating the SRV. Furthermore, for some fracturing stages with few microseismic events induced, the DD tomography could still use events from other stages to determine velocity anomalies for those stages. Therefore, compared to the conventional way of event location-based SRV estimation, the model-based SRV estimation method less depends on the completeness of event detection. For this fracturing job, it can be seen that the well-resolved low Vs anomaly zone does not completely overlap with the induced microseismic events directly related to fracturing process (Fig. 10). As a result, the SRV estimation based on event locations will be different from that estimated by low velocity anomalies. It is true that the DD tomography also relies on event distribution for reliably estimating velocity anomalies. However, when combined with event locations it should better characterize the fractured zone.

\section{CONCLUSIONS}


We have extended the DD tomography method to be applicable for the downhole microseismic monitoring by incorporating the event back azimuth information in addition to the arrival time information to constrain event locations. We demonstrate the effectiveness of the new method on a real microseismic dataset collected for hydraulic fracturing of shale gas reservoirs. The event location results indicate our new method can better characterize the fracture distribution. In addition to microseismic events directly created by hydraulic fracturing, we also identify microseismic events that are related to activation of existing faults due to the increased fluid pore pressure in the fault zone. The tomography results clearly show low velocity anomalies associated with the existing fault zones and potentially provide flow paths. Around the fracturing zone the induced microseismicity is also associated with low velocity anomalies, likely due to the existence of fractures and fluids. Therefore, the zone of low Vp and Vs anomalies could be used as a proxy for the estimation of SRV. The new way of SRV estimation does not depend on the completeness of microseismic events and thus can provide a more accurate and less biased estimation.

\section{ACKNOWLEDGEMENTS}

This research is partly supported by the Natural National Science Foundation of China under Grant Number of 41274055 and Anhui Wantai Geophysical Technology. We are grateful for the anonymous reviewer for providing constructive comments that are helpful for improving this 
paper.

\section{REFERENCES}

Castellanos, F. \&M. Van der Baan, 2013. Microseismic event locations using the double-difference algorithm, CSEG Recorder, 38, 26-37.

Christensen, N.I., 1989, Pore pressure, seismic velocities, and crustal structure, in Pakiser, L.C., and Mooney, W.D., eds., Geophysical framework of the continental United States: Geological Society of America Memoir 172, p. 783-798.

Das, I., and M. D. Zoback, 2011. Long period long duration seismic events during hydraulic fracture stimulation of a shale gas reservoir, LeadingEdge, 30, 778-786.

Das, I., and M. D. Zoback, 2013a. Long-period long-duration seismic events during hydraulic stimulation of shale and tight gas reservoirs — Part 1: Waveform characteristics, Geophysics, 78, KS97-KS105.

Das, I., and M. D. Zoback, 2013b. Long-period long-duration seismic events during hydraulic stimulation of shale and tight gas reservoirs — Part 2: Location and mechanisms, Geophysics, 78,KS107-KS118.

Du, W., C. Thurber\& D. Eberhart-Phillips, 2004. Earthquake relocation using cross-correlation time delay estimates verified with the bispectrum method, Bull. Seism. Soc. Am.,94, 856-866.

Eisner L., Fischer T. \& Rutledge T., 2009.Determination of S-wave slowness from a linear array of borehole receivers, Geophys. J. Int.,176, 31-39.

Eisner L., et al., 2010.Comparison of surface and borehole locations of induced seismicity, Geophys. Prospect.,58(5), 809-820. 
Ellsworth W., 2013, Injection-induced earthquake, Science, 341, 1225942, DOI: 10.1126/science.1225942.

Erwemi, A., et al., 2010. Anisotropic Velocity Modeling For Microseismic Processing: Part 3-borehole Sonic Calibration Case Study. In 2010 SEG Annual Meeting. Society of Exploration Geophysicists.

Fischer, T., et al., 2008.Microseismic signatures of hydraulic fracture growth in sediment formations: Observations and modeling, J. geophys. Res., 113(B2), 1-12.

Jones, G.A., et al., 2010. Improved microseismic event location by inclusion of a priori dip particle motion: A case study from Ekofisk, Geophys. Prospect.,58(5), 727-737.

Lee, W. H. K., \& S. W. Stewart, 1981. Principles and applications of microearthquake networks, Adv. Geophys. Suppl, 2, 293 pp.

Li, J.L. et al.,2011. Focal mechanism determination of induced microearthquakes in an oil field using full waveforms from shallow and deep seismic networks, Geophysics,76,WC87-WC101.

Magotra, N., Ahmed, N. \& Chael, E., 1989. Single-station seismic event detection and location, IEEE Trans. Geosci. Remote Sens., 27, 15-23.

Maxwell,S.C. et al.,2010.Petroleum reservoir characterization using downhole microseismic monitoring, Geophysics,75,A129-A137.

Mayerhofer M, et al., 2010. What Is Stimulated Reservoir Volume?. SPE Production \& Operations, 25(1): 89-98.

Paige, C. C., \& M. A. Saunders, 1982. LSQR: sparse linear equations and least squares problems, ACM Trans. Math. Softw, 8, no. 2, 195-209.

Pearson, C., 1981. The Relationship Between Microseismicity and High Pore Pressures During 
Hydraulic Stimulation Experiments in Low Permeability Granitic Rocks, J. geophys. Res., 86(B9), 7855-7864.

Phillips et al.,1989. Induced Microearthquake Patterns and Oil-Producing Fracture Systems in the Austin Chalk, Tectonophysics, 289, 153-169.

Rutledge, J.T. \& Phillips, W.S., 2003. Hydraulic stimulation of natural fractures as revealed by induced microearthquakes, Carthage Cotton Valley gas field, east Texas, Geophysics, 68,441-452.

Thurber, C. H, 1983. Earthquake locations and three-dimensional crustal structure in the Coyote Lake area, central California, J. Geophys. Res, 88, 8226-8236.

Thurber, C. H., 1992. Hypocenter-velocity structure coupling in local earthquake tomography, Phys. Earth Planet. Interiors, 75, 55-62.

Um, J., \& C. H. Thurber, 1987. A fast algorithm for two-point seismic ray tracing, Bull. Seism. Soc. Am, 77, 972-986.

VanDecar, J. C., \& R. S. Crosson, 1990. Determination of teleseismic relative phase arrival times using multi-channel cross-correlation and least-squares, Bull. Seism. Soc. Am.,80, $150-169$.

Waldhauser,F.\&Ellsworth,W.L.,2000. A double-difference earthquake location algorithm: method and application to the northern Hayward fault, California, Bull.seism.Soc.Am.,90,1353-1368.

Yang, Y., et al., 2013. An integrated geomechanical and microseismic study of multi-well hydraulic fracture stimulation in the Bakken formation, URTeC 18031. 
Zeng, X., et al., 2014. Surface Microseismic Monitoring of Hydraulic Fracturing of a Shale-Gas Reservoir Using Broadband Seismic Sensors, Seismological Research Letters, 85, 668-677, doi: $10.1785 / 0220130197$

Zhang, H.J. \& Thurber, C.H., 2003. Double-difference tomography: the method and its application to the Hayward Fault, California,Bull.seism.Soc.Am.,93,1875-1889.

Zhang, H.J. et al., 2009.Passive seismic tomography using induced seismicity at a petroleum field in Oman, Geophysics, 74, WCB67.

Zimmer, U., 2011a. Calculating stimulated reservoir volume (SRV) with consideration of uncertainties in microseismic-event locations. In Canadian Unconventional Resources Conference. Society of Petroleum Engineers.

Zimmer, U., 2011b. Microseismic design studies, Geophysics, 76,WC17-WC25. 

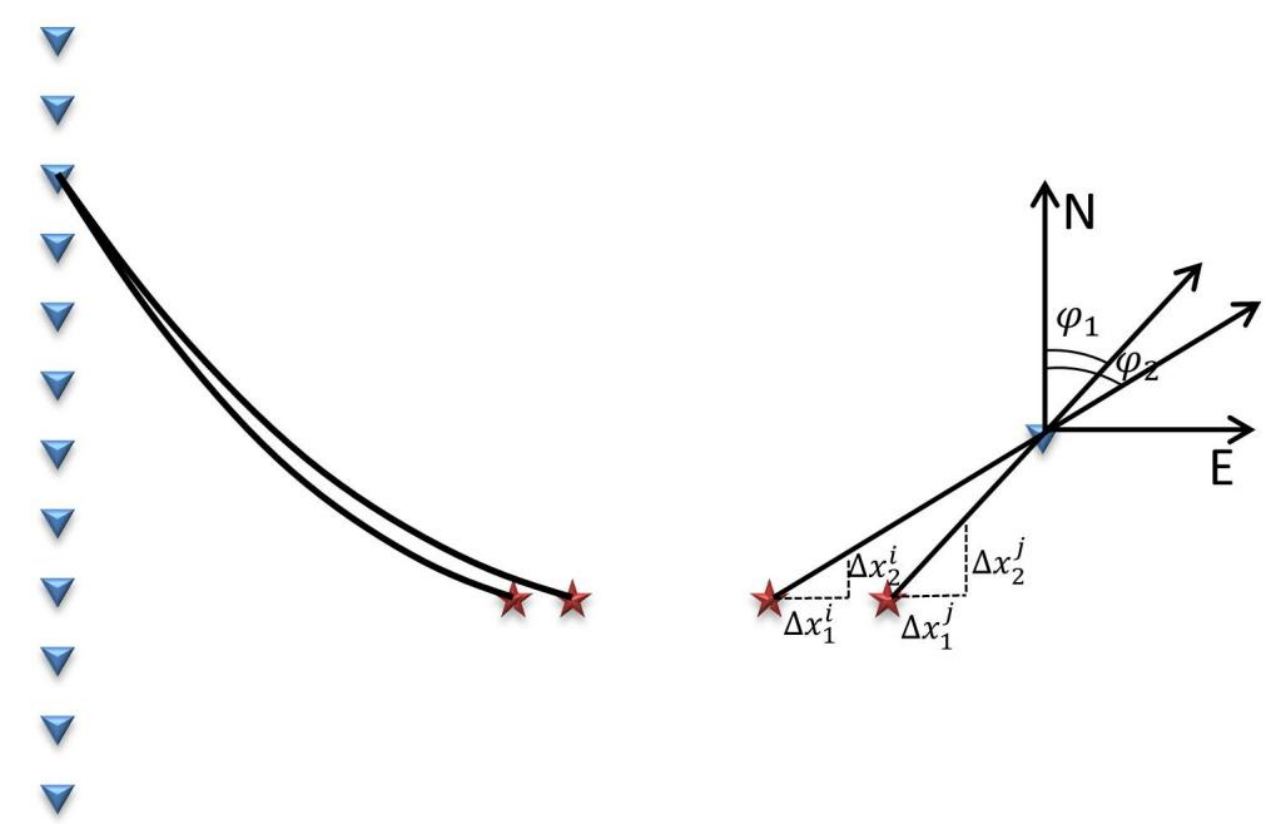

Figure 1 Illustration of the back azimuth constrained double-difference tomography method. Left: ray paths from an event pair to a common receiver in a vertical linear array. Right: the geometrical relation expressed by Equation (5). 


\section{(a)}

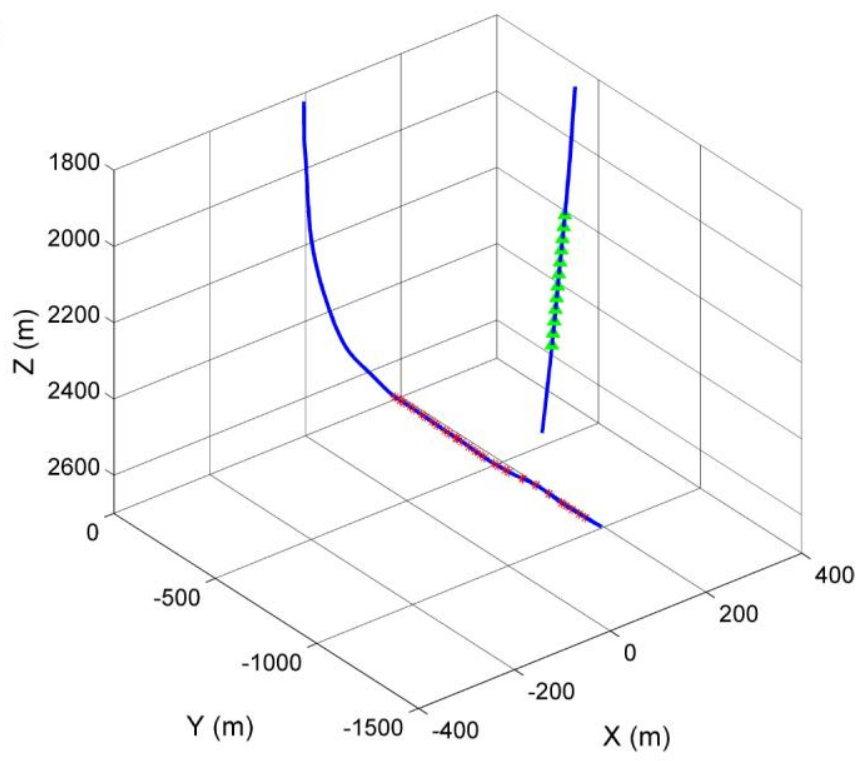

(b)

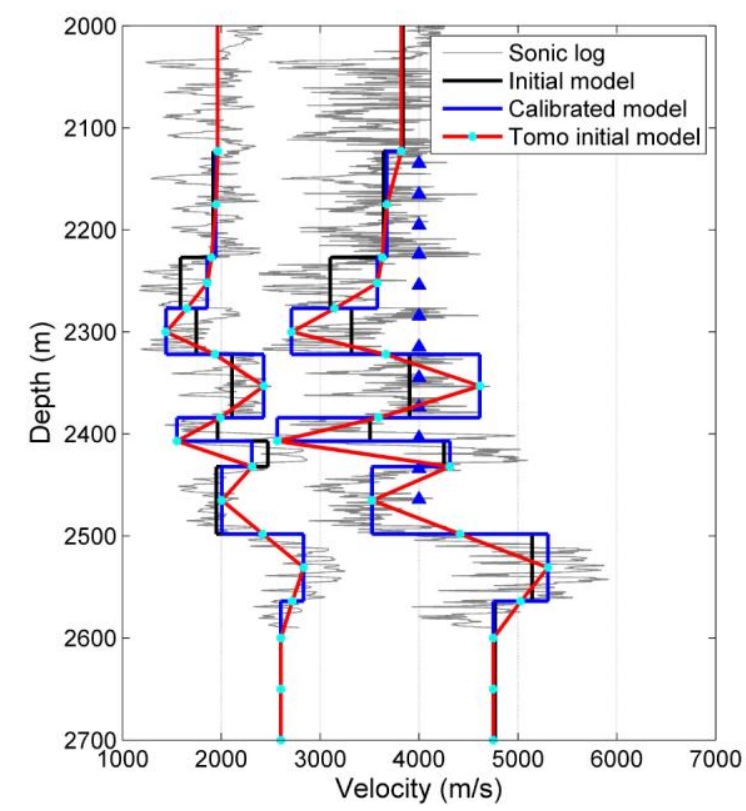

Figure 2 Observation geometry for downhole microseismic monitoring (a) and 1D velocity profiles for microsiesmic location (b). The fracturing well is represented by blue line with red stars (perforation shots) and the receivers are represented by green triangles. Black line is the $1 \mathrm{D}$ velocity profile extracted from acoustic logging data (gray line). The blue line is the calibrated model and the initial velocity model for tomography is represented by the red line with cyan squares. 

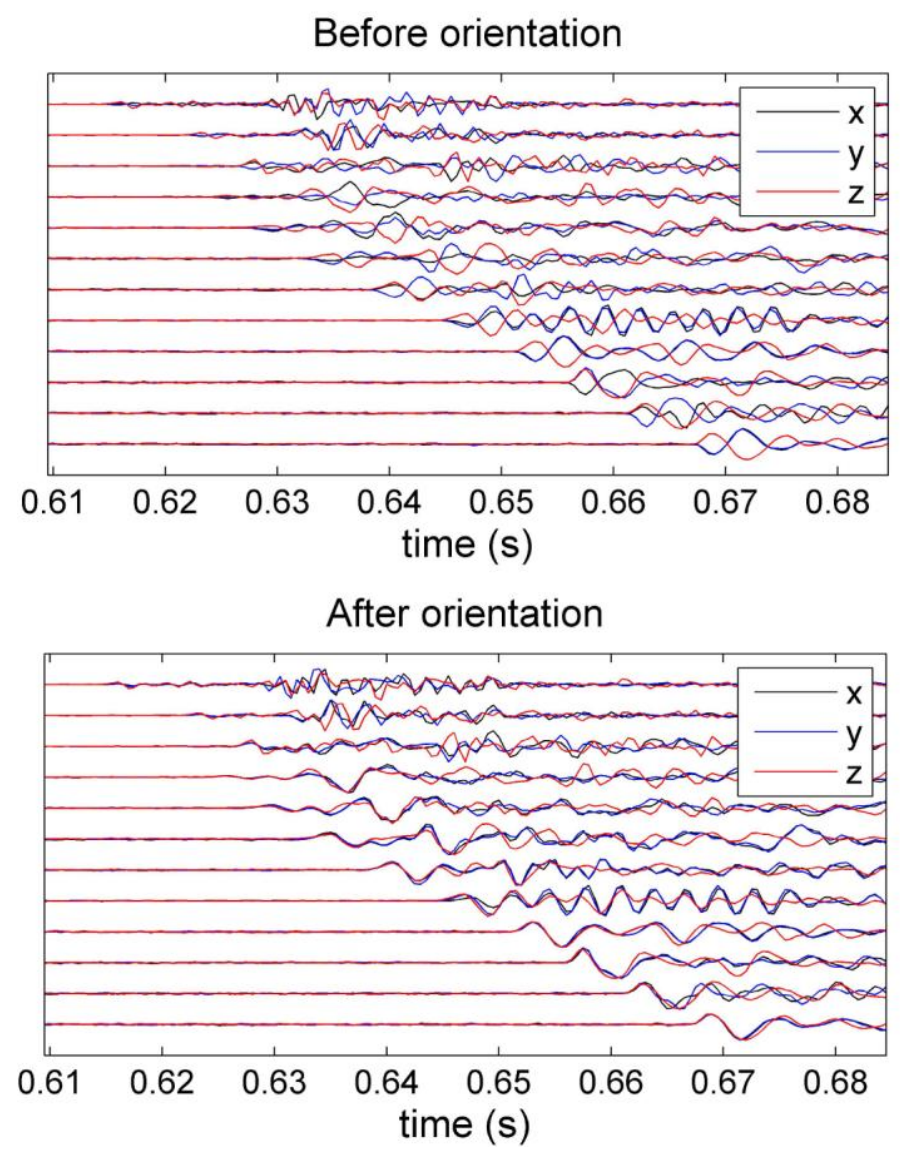

Figure 3 Comparison of three-component waveforms from one perforation shot before and after the orientation of the horizontal components of the $3 \mathrm{C}$ receivers in the vertical monitoring well. 

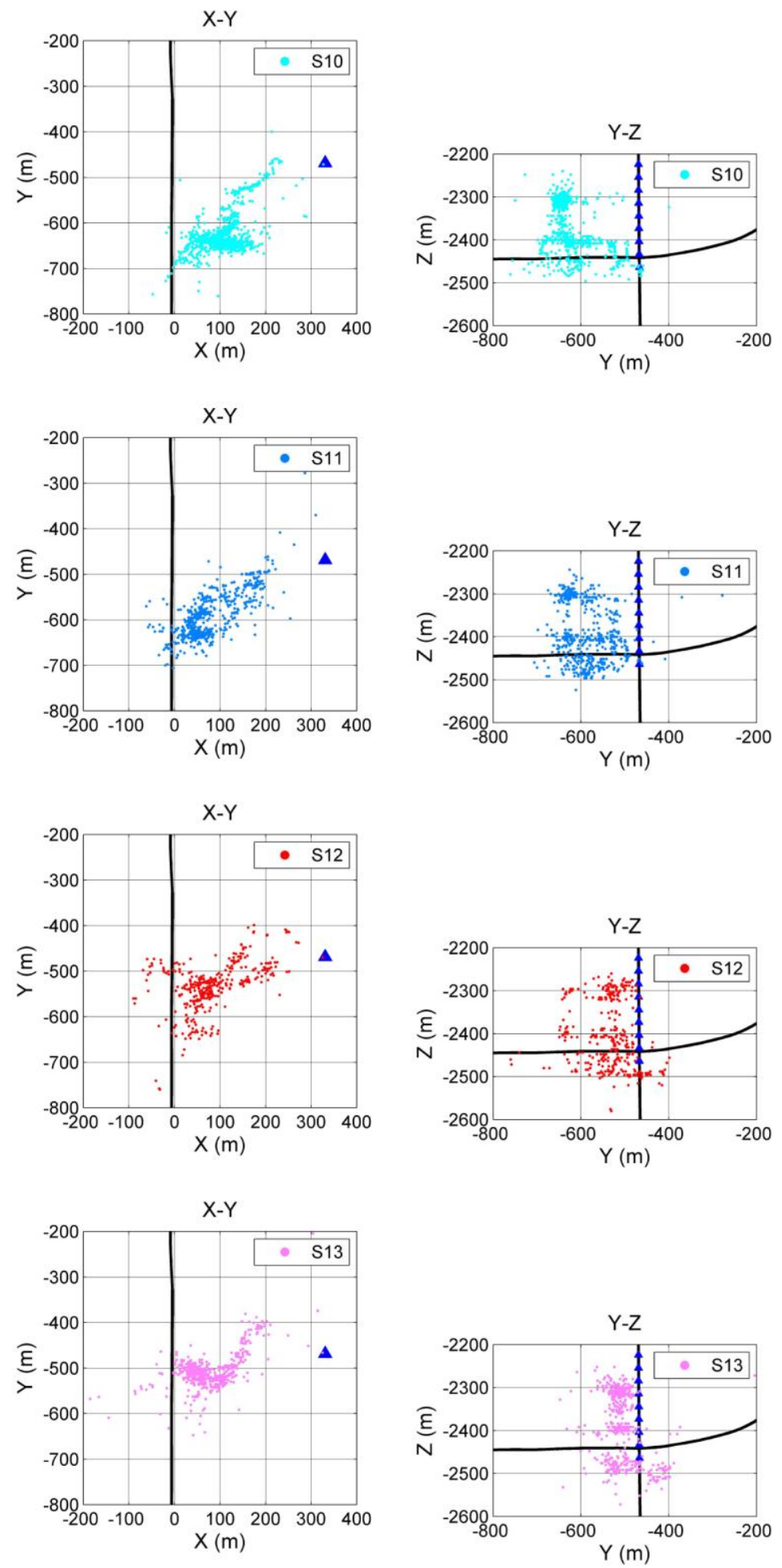

Figure 4 Event locations in the X-Y and Y-Z cross-sections for selected stages 10-13 from the grid search location method. 
(a) P catalog

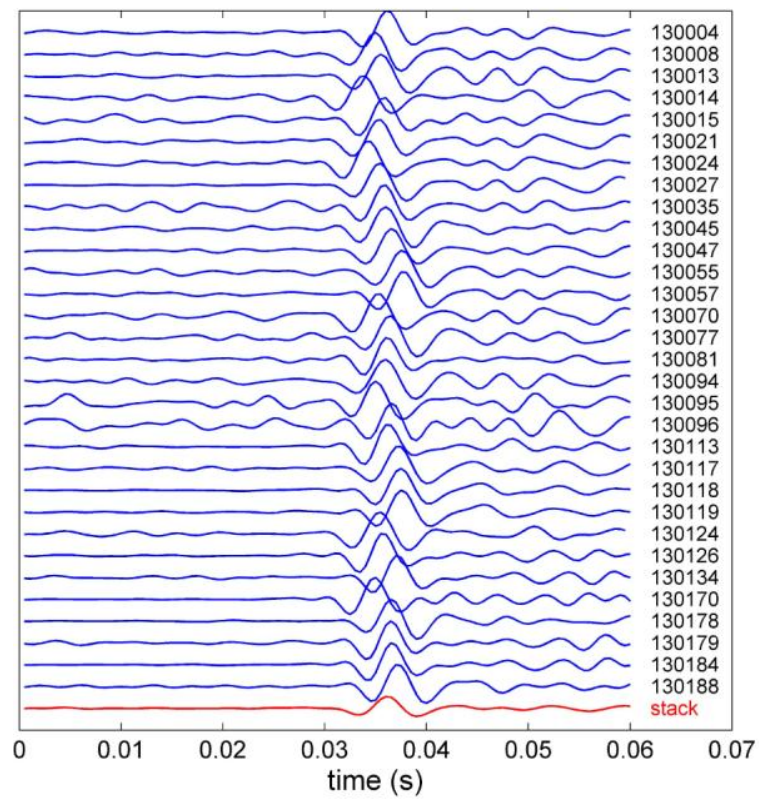

(c) $\mathrm{S}$ catalog

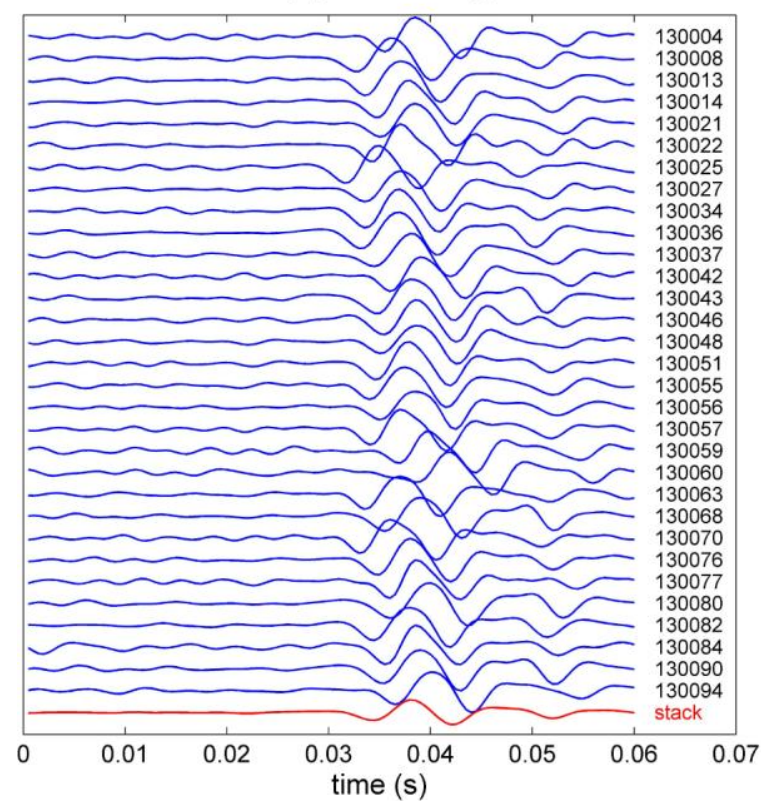

(b) $\mathrm{P}$ cross-correlation

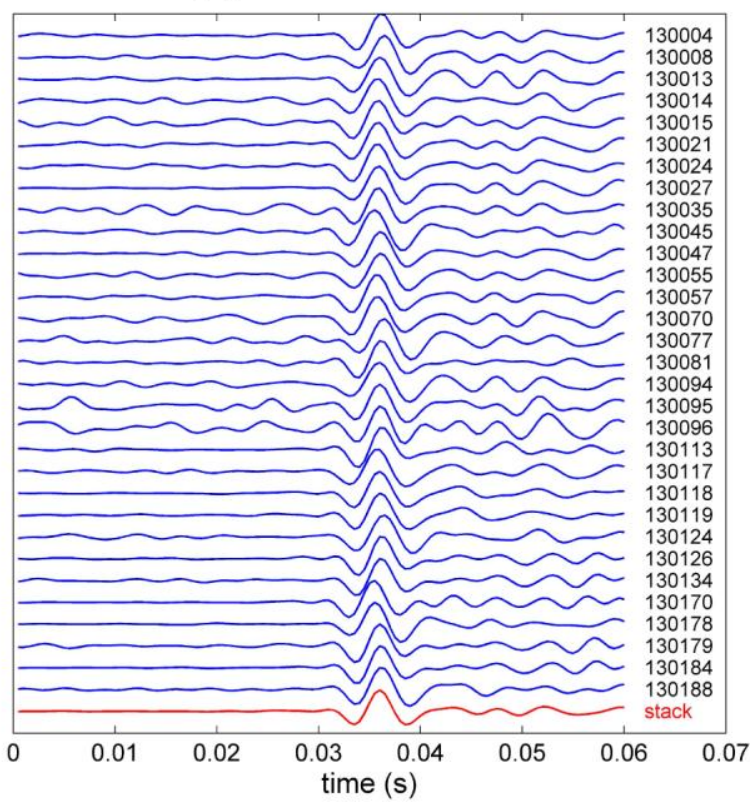

(d) $\mathrm{S}$ cross-correlation

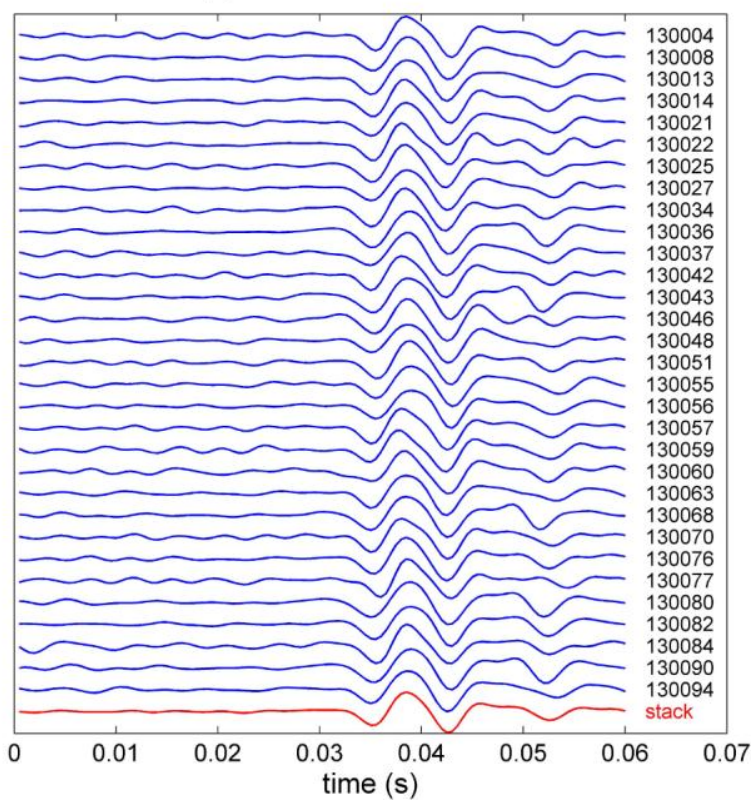

Figure 5 Comparison of waveform alignment for $\mathrm{P}$ (top) and $\mathrm{S}$ (bottom) waves based on catalog picks and waveform cross correlation times. The stacked waveforms are shown as red lines in each panel. (a) and (b) P waveform alignment according to catalog P picks and waveform cross-correlation P times, respectively. (c) and (d) $\mathrm{S}$ waveform alignment according to catalog $\mathrm{S}$ picks and waveform cross-correlation $\mathrm{S}$ times, respectively. 

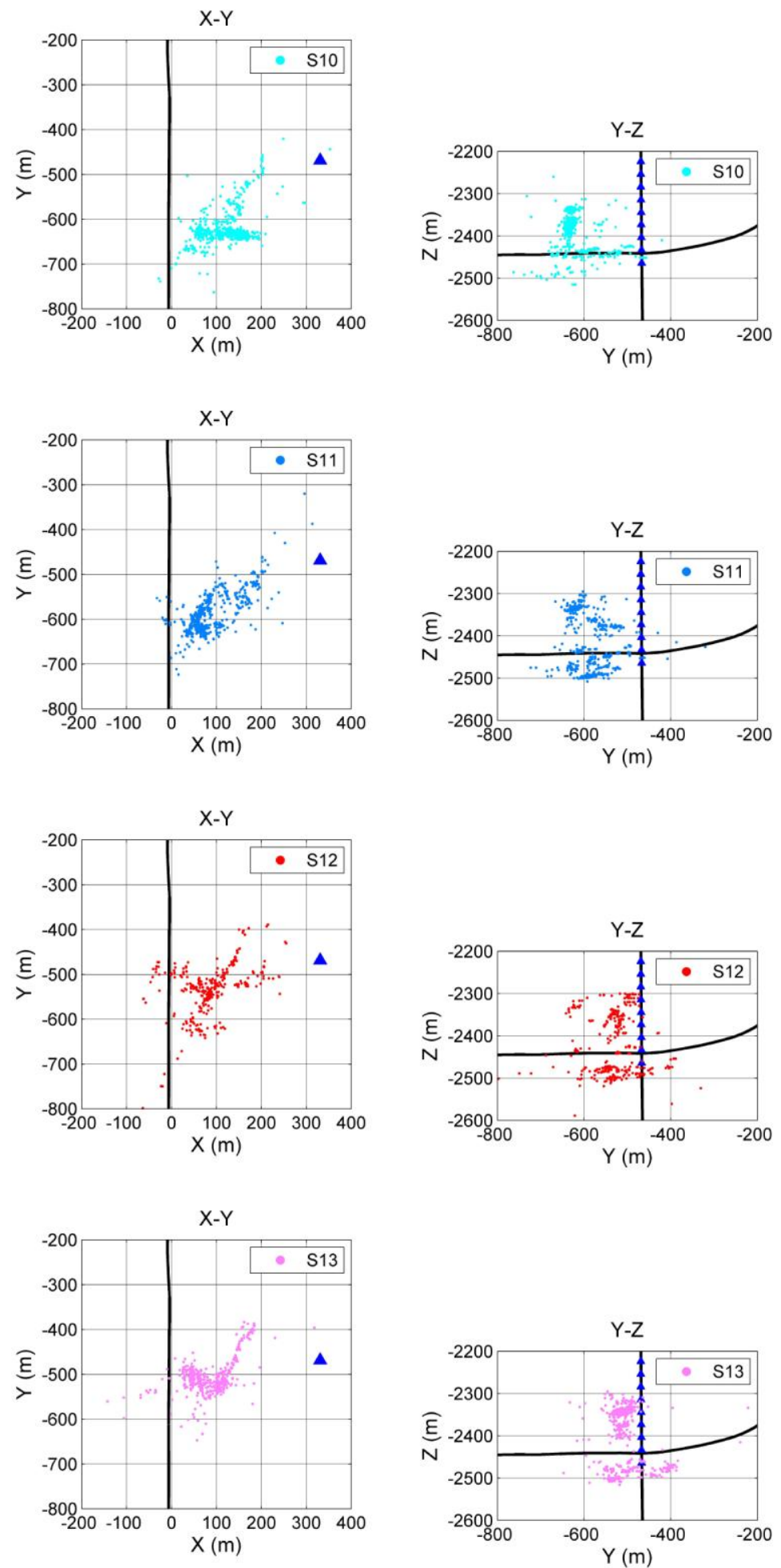

Figure 6 Event locations in the X-Y and Y-Z cross-sections for selected stages 10-13 from extended double-difference tomography method. 
(a)

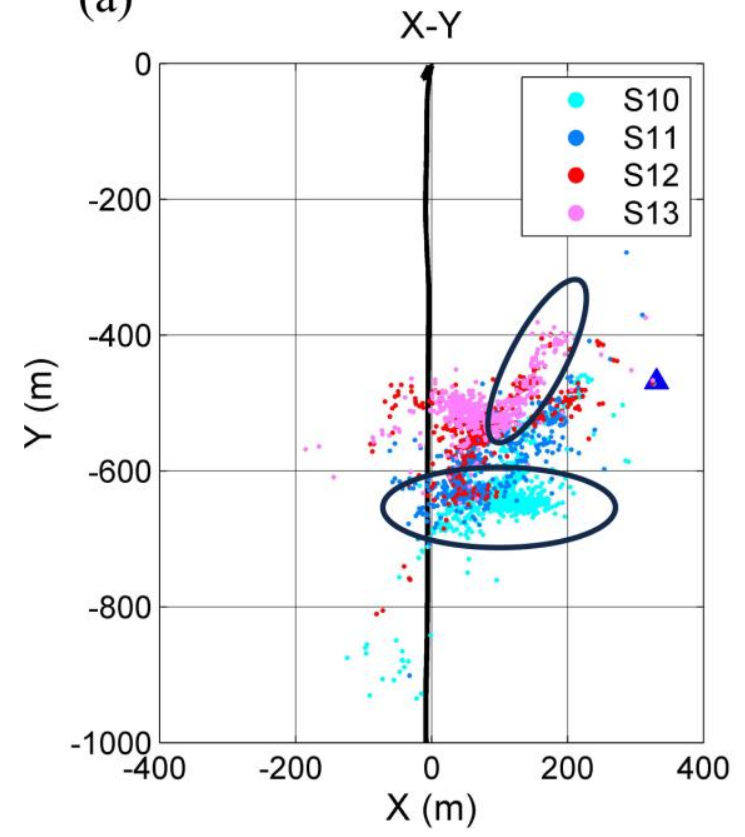

(c)

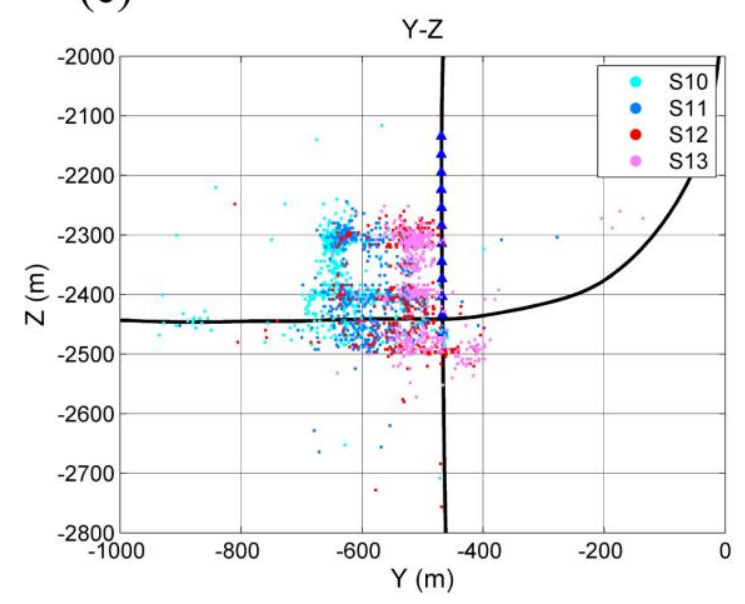

(b)

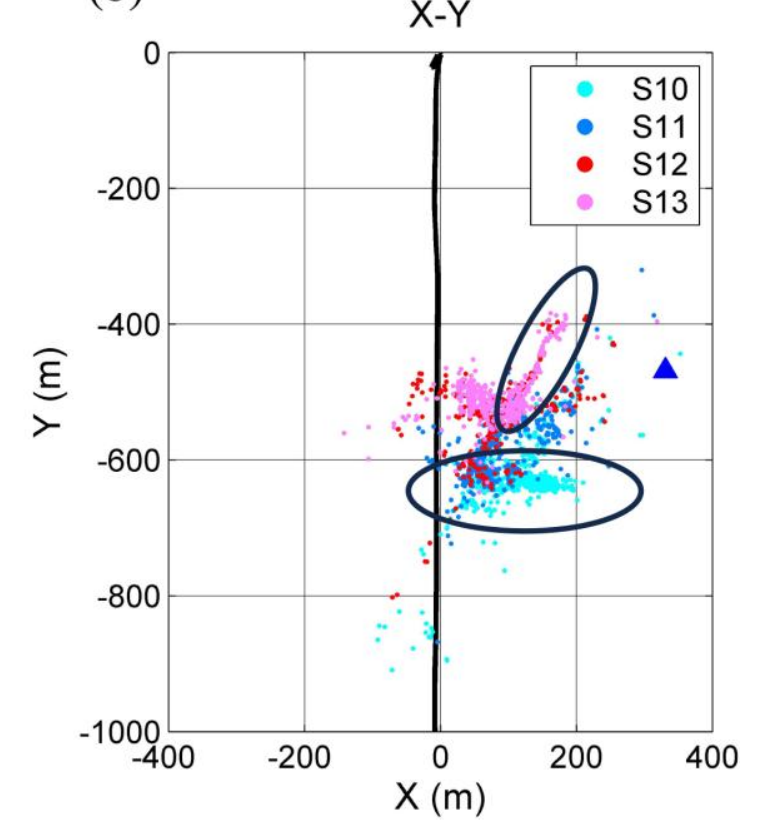

(d)

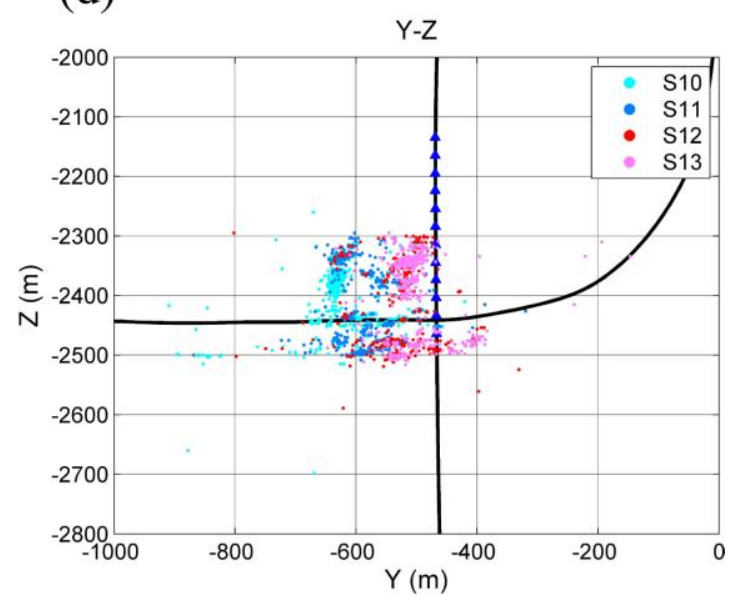

Figure 7 Comparison of all microseismic locations from stages 10-13 for the grid search location method $(7 \mathrm{a}, 7 \mathrm{c})$ and the extended DD tomography method (7b, 7d) at X-Y and Y-Z planes, respectively. 

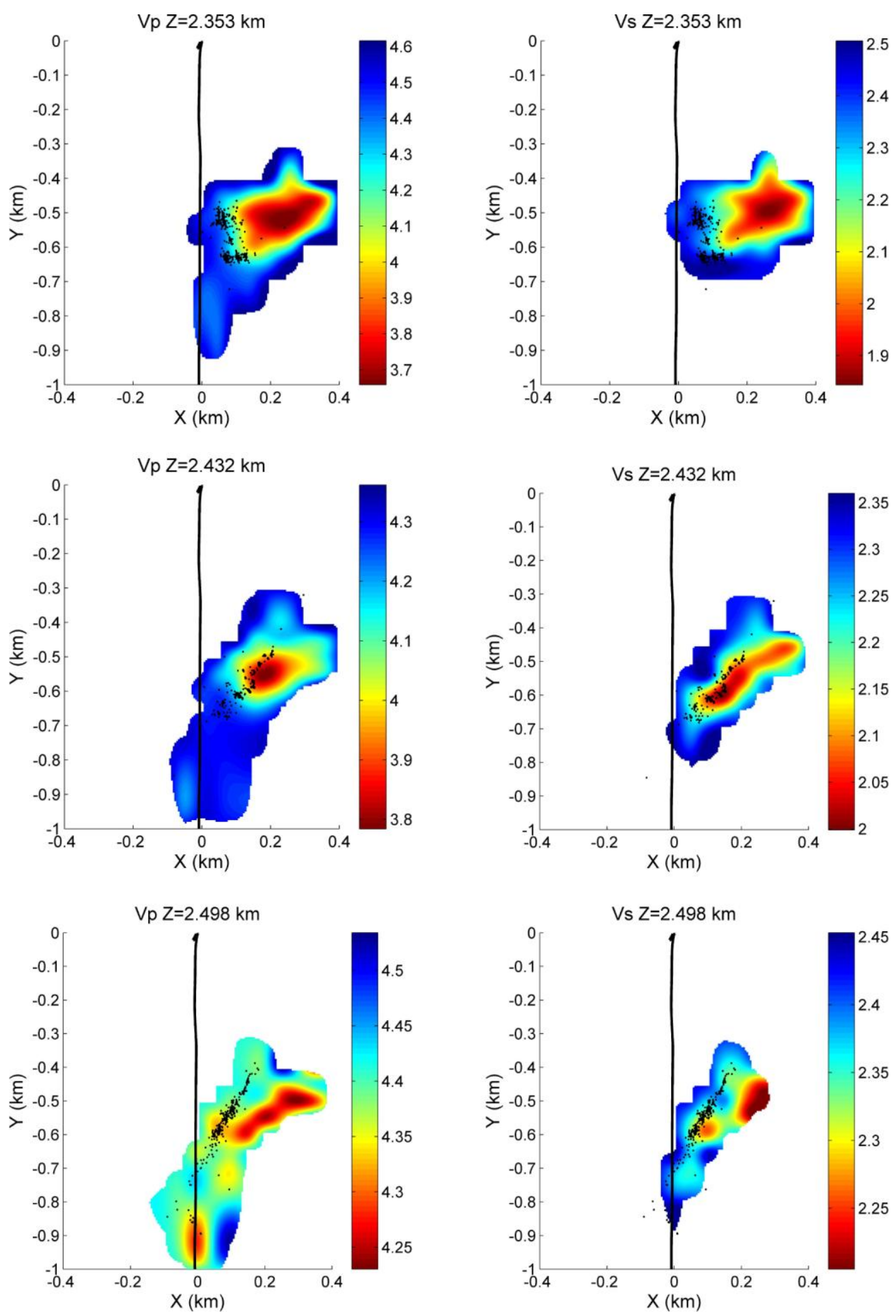

Figure 8 Horizontal slices of the inverted (left) Vp and (right) Vs models at depths of 2.353, 2.432 and $2.498 \mathrm{~km}$, respectively. 

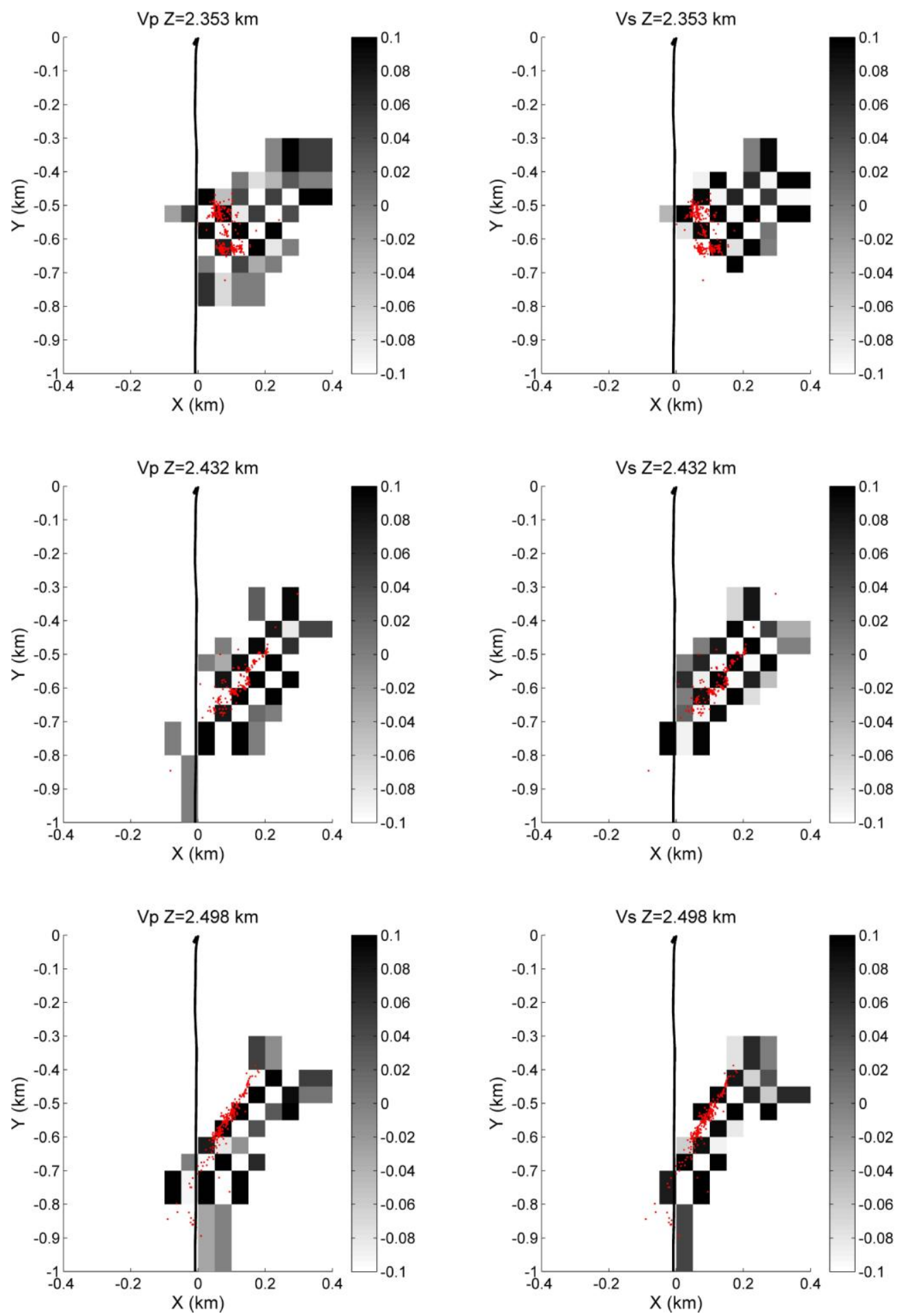

Figure 9 Horizontal slices of the recovered checkerboard models for (left) Vp and (right) Vs at depths of $2.353,2.432$ and $2.498 \mathrm{~km}$, respectively. 

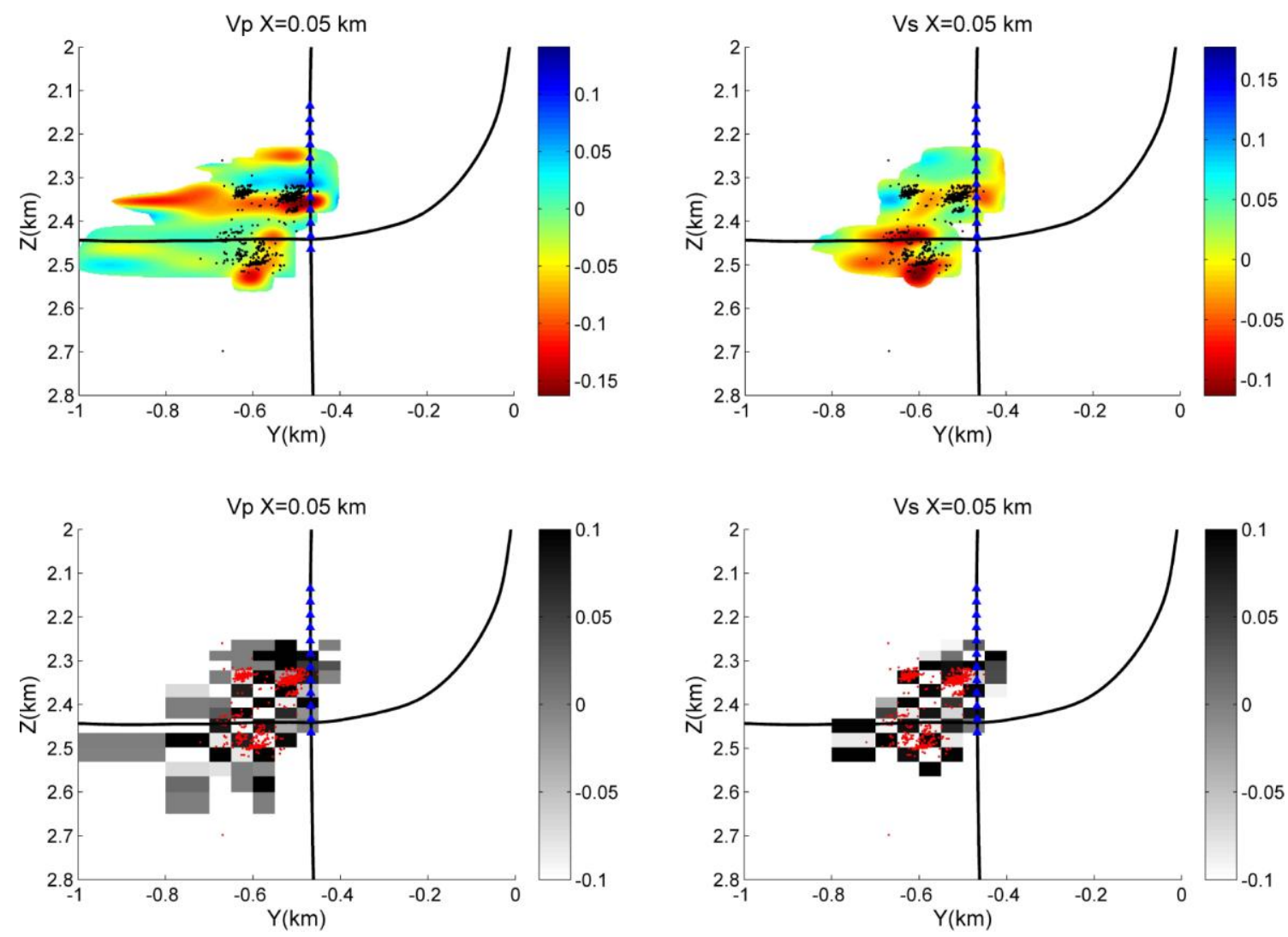

Figure 10 The velocity perturbations (top) and the corresponding recovered checkerboard models (bottom) for Vp (left) and Vs (right) in the Y-Z plane through $\mathrm{X}=0.05 \mathrm{~km}$. 

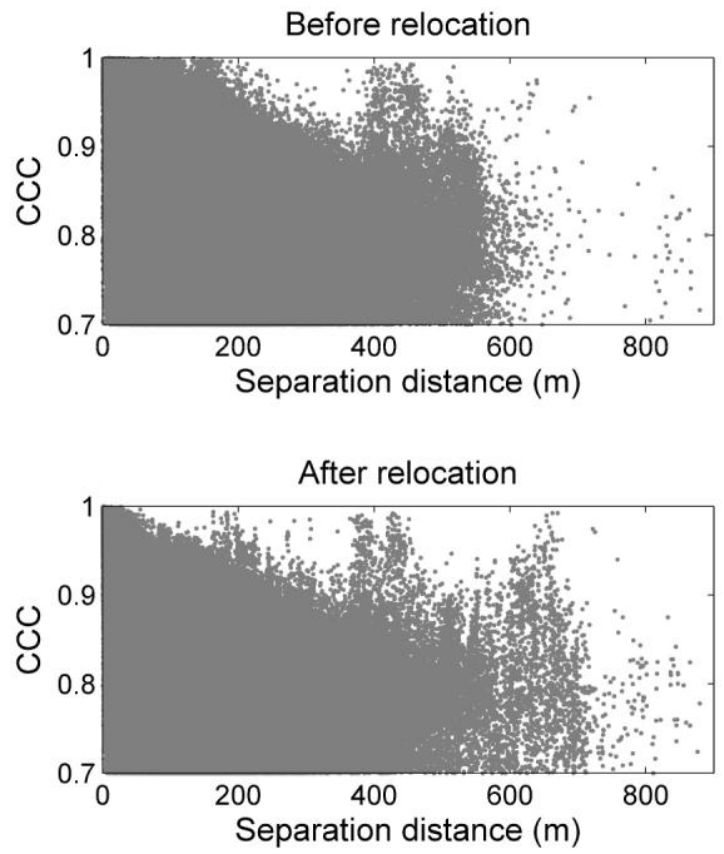

Figure 11 Comparison of the distribution of cross correlation coefficients (CCCs) for event pairs with respect to the inter-event distances (a) before and (b) after relocation by the DD tomography method. 